\title{
Peptide Growth Factors in Tracheal Aspirates of Mechanically Ventilated Preterm Neonates
}

\author{
NAMASIVAYAM AMBALAVANAN AND ZUZANA E. NOVAK \\ Division of Neonatology, Department of Pediatrics, University of Alabama at Birmingham, Birmingham, \\ Alabama, U.S.A.
}

\begin{abstract}
ABST
Basic fibroblast growth factor (bFGF or FGF-2), vascular
endothelial growth factor (VEGF), and endothelin-1 (ET-1) are
peptide growth factors (PGF) mediating normal lung develop-
ment, maturation, injury, and repair. These PGF may therefore be
involved in the pathogenesis of bronchopulmonary dysplasia
(BPD). We hypothesized that elevated levels of these PGF in
tracheal aspirates would be associated with a) BPD and/or death;
b) markers of cell injury and apoptosis; and c) chorioamnionitis,
a risk factor for BPD. Tracheal aspirates collected in 29 preterm
(<34 wk gestation, $500-2000 \mathrm{~g}$ birth weight), mechanically
ventilated infants on d 1 of life were assayed for PGF and
histone-associated DNA fragments by ELISA and for LDH by
enzyme assay. Clinical and pathologic examination was per-
formed for chorioamnionitis. BPD was defined as oxygen re-
quirement/mechanical ventilation at $28 \mathrm{~d}$ postnatal age. The birth
weight (mean \pm SE) was $1009 \pm 85 \mathrm{~g}$ and median gestational
age was 26 wk (range, $22-33$ ). Eighteen infants died or devel-
oped BPD. bFGF levels were elevated in infants who died or
developed BPD [median ( $25 \%, 75 \%$ ) level of 36 (23, 44 ) pg/mL
\end{abstract}
Mortality and BPD are common in preterm neonates requiring mechanical ventilation. Factors involved in the development of BPD include impairment of normal lung development in association with lung injury and repair. PGF, including bFGF (FGF-2) $(1,2)$, other members of the fibroblast growth factor family such as FGF-7/keratinocyte growth factor (KGF) and FGF-10 (3-7), epidermal growth factor (EGF) $(8,9)$, endothelin-1 $(10,11)$, platelet derived growth factor (PDGF) $(6,12,13)$, transforming growth factor $\beta-1(7,9)$, and VEGF (14) are important in lung anatomic and functional development. There is preliminary evidence that ET-1 $(15,16)$ and VEGF $(14,17)$ may be involved in the pathogenesis of BPD in infants, and that bFGF is elevated in the airway epithelial lining fluid in adults with acute respiratory distress syndrome (ARDS) (18). We performed a pilot study to test the hypoth-

Received January 18, 2002; accepted July 5, 2002.

Correspondence: Namasivayam Ambalavanan, MD, Assistant Professor, Division of Neonatology, 525 New Hillman Bldg., 619 South 19th Street, University of Alabama at Birmingham, Birmingham, AL 35249, U.S.A.; e-mail: ambal@sprynet.com

DOI: 10.1203/01.PDR.0000047656.17766.39 versus $14(6,30)$ in the survivors without $\mathrm{BPD}, p=0.01]$. bFGF levels correlated with apoptosis $(r=0.73, p<0.001)$ and $\mathrm{LDH}$ levels $(r=0.59, p<0.001)$. VEGF and ET-1 levels were not associated with apoptosis or with BPD/death. PGF levels were not associated with chorioamnionitis. We conclude that elevated bFGF levels in the preterm trachea correlate with BPD/death and markers of cell injury and apoptosis but not with chorioamnionitis. We speculate that bFGF may play a role in the development of BPD. (Pediatr Res 53: 240-244, 2003)

\section{Abbreviations}

bFGF, basic fibroblast growth factor (fibroblast growth factor-2)

BPD, bronchopulmonary dysplasia

ET-1, endothelin-1

LDH, lactate dehydrogenase

PGF, peptide growth factor

VEGF, vascular endothelial growth factor eses that elevated levels of bFGF, ET-1, and VEGF in tracheal aspirates of mechanically ventilated preterm neonates would be associated with a) BPD and/or death; b) markers of cell injury and apoptosis; and c) chorioamnionitis, a risk factor for BPD.

\section{METHODS}

Subjects. This was a prospective study on 30 preterm infants admitted to the Regional Neonatal Intensive Care Unit at the University of Alabama at Birmingham from April to September 2000. Infants were eligible if they were $<34$ wk gestational age and weighed 501-2000 g, and received mechanical ventilation on the first day of life. The protocol was approved by the institutional review board, and informed consent was obtained for each participant before entry into the study.

Definitions. A clinical diagnosis of chorioamnionitis was based on the presence of one or more of the following criteria: preterm prolonged rupture of membranes $>24 \mathrm{~h}$, maternal fever $>38^{\circ} \mathrm{C}$, maternal sepsis, foul-smelling or purulent amniotic fluid, and uterine tenderness. Pathologists masked to the 
study established a histologic diagnosis of maternal chorioamnionitis.

BPD was defined as the need for supplemental oxygen or mechanical ventilation at $28 \mathrm{~d}$ postnatal age, in association with radiologic changes consistent with $\mathrm{BPD}\left(\mathrm{BPD}_{28 \mathrm{~d}}\right)$. Additional analysis was also performed using the alternative definition of BPD as supplemental oxygen or mechanical ventilation at $36 \mathrm{wk}$ postmenstrual age $\left(\mathrm{BPD}_{36 \mathrm{wk}}\right)$. Death was defined as mortality before hospital discharge or $120 \mathrm{~d}$ hospital stay.

Tracheal aspirates. Tracheal aspirates were collected after informed consent was obtained. Aspiration of the endotracheal tube was only undertaken when clinically indicated. All tracheal aspirates were collected before $24 \mathrm{~h}$ of age, after surfactant administration. A standardized procedure was used. After endotracheal instillation of $1 \mathrm{~mL} / \mathrm{kg}$ of normal saline, three to five breaths were given with the ventilator or flow-inflating resuscitation bag. A premeasured suction catheter was advanced through the endotracheal tube and suctioning performed just distal to the tip of the tube. Fluid was aspirated into the Leuken trap, placed on ice, and processed within $20-40 \mathrm{~min}$. Samples with visible blood were discarded. All samples were diluted with $3 \mathrm{~mL}$ of PBS and centrifuged at $12,000 \times g$ for $10 \mathrm{~min}$ at $4^{\circ} \mathrm{C}$. Supernatants were stored at $-70^{\circ} \mathrm{C}$ until analyzed for PGF by ELISA. As recommended by the European Respiratory Task Force on Bronchoalveolar Lavage in children (19), we did not correct our results for the dilution during the lavage procedure, and expressed our data per milliliter of tracheal aspirate, as results obtained by urea dilution or correction for protein concentration may show more inaccuracy because of increased vascular permeability and lung inflammation in sicker infants. All assays were performed by investigators masked to outcome until completion of the assays. Wright-stained smears of cytospin slides of tracheal aspirates were examined for cell density (cells/high power field), percentage of the cells that were white blood cells (WBC), and differential WBC count (percentage polymorphonuclear leukocytes) by an observer masked to patient identity and clinical outcome. The average number of polymorphonuclear leukocytes (neutrophils) was then calculated from these indices.

Analysis for PGF. PGF were measured by ELISA. bFGF was estimated using a high-sensitivity quantitative sandwich enzyme immunoassay (ELISA) obtained from R \& D Systems (Minneapolis, MN, U.S.A.). This assay used MAb specific for bFGF and had a sensitivity of $0.2 \mathrm{pg} / \mathrm{mL}$, with no crossreactivity or interference from acidic FGF, FGF-4, -5,-6, or -7. VEGF was also assayed by a similar quantitative sandwich enzyme immunoassay from R \& D Systems. The sensitivity of the VEGF assay was $10 \mathrm{pg} / \mathrm{mL}$, without significant crossreactivity with or interference from other PGF. ET-1 was estimated using an ELISA obtained from Amersham Pharmacia Biotech (Piscataway, NJ, U.S.A.). This ELISA was specific for human ET-1 (and ET-2), with $<0.1 \%$ cross-reactivity to Big ET-1 or ET-3. The sensitivity of this assay was 0.5 $\mathrm{fmol} / \mathrm{well}(12.5 \mathrm{pg} / \mathrm{mL})$. Intra-assay variability in all the PGF assays was $<10 \%$.

Quantitation of apoptosis and cell injury. Apoptosis was estimated by a quantitative sandwich enzyme immunoassay (Cell Death Detection ELISA, Roche Diagnostics, Indianapolis, IN, U.S.A.) using mouse MAb directed against DNA and histones, permitting the determination and quantitation of mono- and oligonucleosomes in the supernatant of the tracheal aspirate. The mono- and oligonucleosomes are evidence of DNA fragmentation produced during apoptosis, and are responsible for the "DNA-laddering" on agarose gels.

Cell injury was estimated by measurement of cytoplasmic LDH in the cell-free component (supernatant) of the tracheal aspirates, which is an indicator of membrane integrity. Damaged cells with loss of cell membrane integrity leak LDH into the surrounding milieu. LDH was measured by enzyme assay (Sigma Chemical, St. Louis, MO, U.S.A.).

All assays were performed using varying dilutions of positive controls. All PGF assays, the apoptosis assay, and the LDH assay have been previously validated in our laboratory on other samples.

Clinical care. All infants were treated in accordance with standard neonatal intensive care unit protocols. As many infants required mechanical ventilation for only a few days, sequential samples over a period of days or weeks could not be collected.

Statistical analysis. The $t$ test or the Fisher exact test were used as indicated for the comparison of patient characteristics. The Mann-Whitney rank sum test was used for the comparison of PGF levels in infants with normal outcome versus those who died or developed BPD. The Pearson or the Spearman correlation coefficients (depending on the whether the distribution was normally distributed or not) were used to assess the relationship between PGF levels and apoptosis or LDH. The software package SigmaStat v.2.03 (Jandel Scientific, San Rafael, CA, U.S.A.) was used for statistical analysis. All data are shown as median $(25 \%, 75 \%)$ unless otherwise indicated.

\section{RESULTS}

Thirty premature infants were studied. Twenty-nine tracheal aspirates could be analyzed (one sample was lost during processing). The birth weight was $1009 \pm 456 \mathrm{~g}$ (mean $\pm \mathrm{SD}$; range, $517-1910 \mathrm{~g}$ ), and the median gestational age was $26 \mathrm{wk}$ (mean $\pm \mathrm{SD}, 26.6 \pm 2.5 \mathrm{wk}$; range, 22-33 wk). Eighteen of 29 $(62 \%)$ infants were male and 12 of $29(41 \%)$ were Caucasian. Eighteen of $29(60 \%)$ had histologic and clinical evidence of chorioamnionitis. Eighteen of 29 infants developed $\mathrm{BPD}_{28 \mathrm{~d}}$, and nine developed $\mathrm{BPD}_{36 \mathrm{wk}}$. Of the seven infants who died, four died after developing $\mathrm{BPD}_{28 \mathrm{~d}}$ but before developing $\mathrm{BPD}_{36 \mathrm{wk}}$. Infants who developed $\mathrm{BPD}_{28 \mathrm{~d}}$ or died were of a lower gestational age (median, $25.6 \mathrm{wk}$ versus $28 \mathrm{wk} ; p=$ 0.003 ) and had a lower birth weight (mean $\pm \mathrm{SD}, 812 \pm 220 \mathrm{~g}$ versus $1239 \pm 303 \mathrm{~g} ; p<0.001)$, compared with those with a normal outcome. Antenatal steroids were received by 20 infants (five of 11 with normal outcome, and 15 of 18 who developed $\mathrm{BPD}_{28 \mathrm{~d}}$ or died; $p=0.048$ ) and intrapartum antibiotics by 22 infants (six of 11 with normal outcome, and 16 of 18 who developed $\mathrm{BPD}_{28 \mathrm{~d}}$ or died; $p=0.07$ ).

$\boldsymbol{b F G F}$. bFGF was significantly elevated in infants who died or developed $\mathrm{BPD}_{28 \mathrm{~d}}$ (Table 1, Fig. 1). The median level of bFGF was $36 \mathrm{pg} / \mathrm{mL}$ in infants who died or developed $\mathrm{BPD}_{28 \mathrm{~d}}$ versus $13.5 \mathrm{pg} / \mathrm{mL}$ in those who survived without $\mathrm{BPD}_{28 \mathrm{~d}}$. bFGF levels in the nine infants who died or developed 
Table 1. PGF levels in tracheal aspirates of mechanically

ventilated preterm infants in relation to the outcome of $B P D$ $\left(\mathrm{O}_{2} /\right.$ mechanical ventilation at age 28 d) and/or death

\begin{tabular}{cccc}
\hline PGF & $\begin{array}{c}\text { No BPD/death } \\
(n=11)\end{array}$ & $\begin{array}{c}\text { BPD/death } \\
(n=18)\end{array}$ & $p$ Value* \\
\hline bFGF & $13.5(6,30)$ & $36(23,44)$ & .01 \\
VEGF & $290(101,608)$ & $114(11,311)$ & .13 \\
ET-1 & $57(31,135)$ & $77(60,105)$ & .77 \\
\hline
\end{tabular}

Values given in picograms per milliliter [median $(25 \%, 75 \%)]$.

* Mann-Whitney rank sum test.

$\mathrm{BPD}_{36 \mathrm{wk}}[39 \mathrm{pg} / \mathrm{mL}(11,52)]$ showed a trend to be elevated compared with survivors without $\mathrm{BPD}_{36 \mathrm{wk}}[22.5 \mathrm{pg} / \mathrm{mL}(9$, $35) ; p=0.07]$. When only infants who died were considered, bFGF was elevated $[42 \mathrm{pg} / \mathrm{mL}(19,57)]$ compared with survivors $[22.5 \mathrm{pg} / \mathrm{mL}(9,36), p<0.05]$. bFGF was moderately inversely correlated with birth weight (Spearman's $r=-0.55$, $p=0.002$ ) and gestational age (Spearman's $r=-0.45, p=$ 0.02 ), indicating that infants with lower birth weight (who are at higher risk of mortality) had higher levels of bFGF. To identify whether the relationship with birth weight was the reason bFGF was associated with mortality, a backward stepwise regression was performed with mortality as the dependent variable and birth weight, gestational age, and bFGF levels as independent variables. bFGF was most strongly associated with mortality in this model, and birth weight and gestation did not add significantly to the predictive ability of bFGF. When only survivors were considered, higher bFGF levels showed a trend toward association with $\mathrm{BPD}_{28 \mathrm{~d}}$. $\mathrm{bFGF}$ level in survivors with $\mathrm{BPD}_{28 \mathrm{~d}}$ was $30 \mathrm{pg} / \mathrm{mL}(22,38)$ and in survivors without $\mathrm{BPD}_{28 \mathrm{~d}}$ was $13.5 \mathrm{pg} / \mathrm{mL}(6,30), p=0.12$. Therefore, it is unlikely that the association of bFGF with BPD or death is the result of its correlation with birth weight or gestational age.

bFGF levels were not significantly different in infants after chorioamnionitis versus those not exposed to chorioamnionitis (Table 2). bFGF levels correlated well with apoptosis (Spearman's $r=0.73, p<0.001)$ and LDH levels $(r=0.59, p<$ 0.001) (Fig. 1). On the other hand, apoptosis and LDH levels did not correlate well with each other (Spearman's $r=0.27$, $p=0.16$ ).

$\boldsymbol{V E \boldsymbol { G } F}$. VEGF levels were not significantly different in infants who survived without $\mathrm{BPD}_{28 \mathrm{~d}}$ versus those who died or developed $\mathrm{BPD}_{28 \mathrm{~d}}$ (Table 1). VEGF levels in infants who had $\mathrm{BPD}_{36 \mathrm{wk}}$ or died $[105 \mathrm{pg} / \mathrm{mL}(41,315)]$ were also not significantly different from normal survivors $[165 \mathrm{pg} / \mathrm{mL}(15,480)$; $p=0.60]$. VEGF levels showed a statistically nonsignificant trend to be higher in infants after chorioamnionitis versus those not exposed to chorioamnionitis (Table 2). There was no significant correlation between VEGF levels and birth weight (Spearman's $r=0.19, p=0.33$ ) or gestational age (Spearman's $r=0.16, p=0.41$ ). VEGF did not also correlate with LDH levels (Spearman's $r=-0.11, p=0.6$ ) or apoptosis (Spearman's $r=-0.28, p=0.13$ ).

$\boldsymbol{E T}$-1. ET-1 levels were not significantly different in infants who survived without $\mathrm{BPD}_{28 \mathrm{~d}}$ versus those who died or developed $\mathrm{BPD}_{28 \mathrm{~d}}$ (Table 1). ET-1 levels in infants who had $\mathrm{BPD}_{36 \mathrm{wk}}$ or died $[90 \mathrm{pg} / \mathrm{mL}(49,110)]$ were also not significantly different from normal survivors $[66 \mathrm{pg} / \mathrm{mL}(45,116)$;
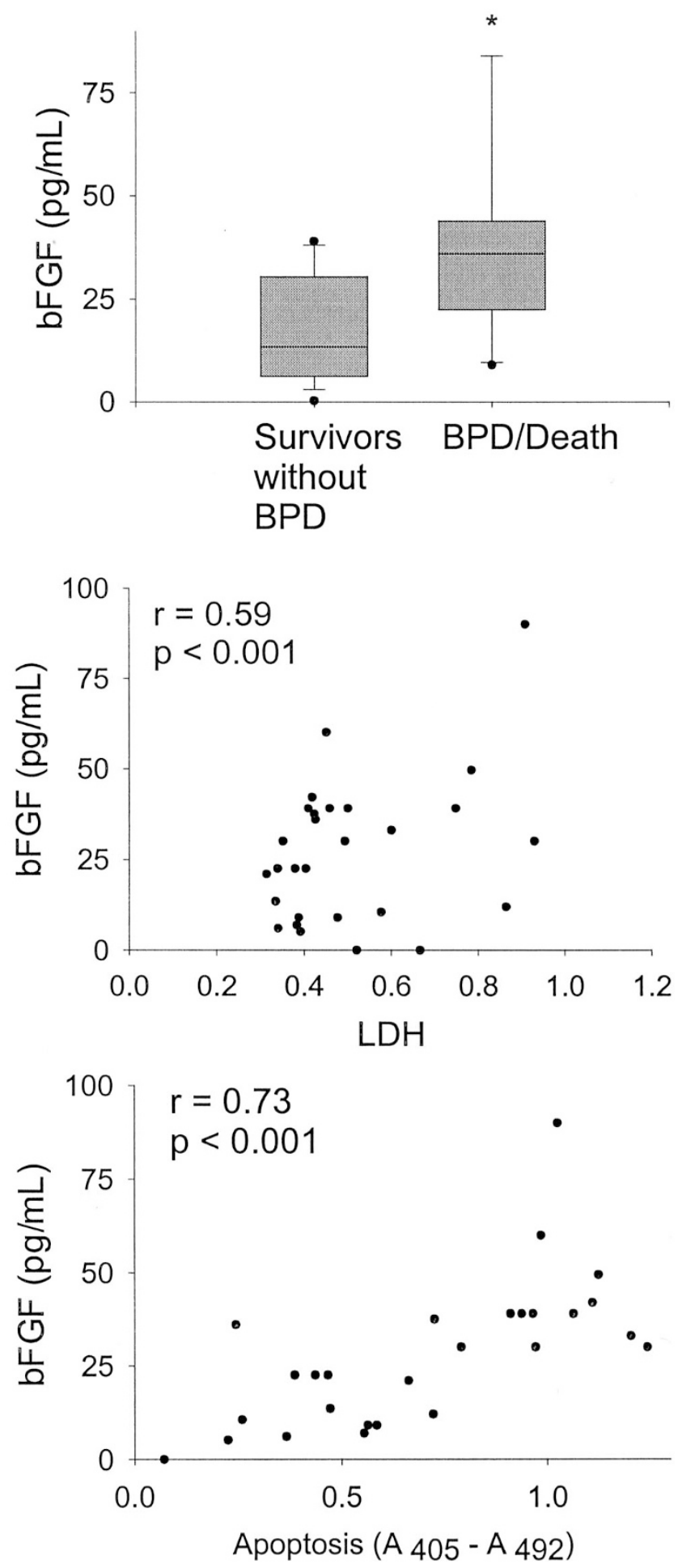

Figure 1. Top panel is a box-plot of tracheal aspirate bFGF in relation to the outcome of $\mathrm{BPD}_{28 \mathrm{~d}}$ /death. The central line in the box indicates the median value and the top and bottom of the box indicate the 75th and 25 th centiles, respectively. The whiskers indicate the 10th and 90th centiles, and the additional dark circles show the outliers. The middle panel is a scatter-plot of bFGF vs LDH levels, and the lower panel is a scatter-plot of bFGF in relation to apoptosis levels. $\left({ }^{*} p<0.05\right.$ vs other group). One outlier has been removed from all panels.

$p=0.60]$. ET-1 levels were also not different in infants after chorioamnionitis versus those not exposed to chorioamnionitis (Table 2). There was no significant correlation between ET-1 
Table 2. PGF levels in tracheal aspirates of mechanically ventilated preterm infants in relation to antecedent chorioamnionitis

\begin{tabular}{cccc}
\hline \multicolumn{1}{c}{$\begin{array}{c}\text { No } \\
\text { PGF }\end{array}$} & $\begin{array}{c}\text { Chorioamnionitis } \\
(n=11)\end{array}$ & $\begin{array}{c}\text { Chorioamnionitis } \\
(n=18)\end{array}$ & $p$ Value* \\
\hline bFGF & $22.5(15,39)$ & $30(9,39)$ & .81 \\
VEGF & $96(4,148)$ & $323(105,600)$ & .06 \\
ET-1 & $66(39,92)$ & $93(57,135)$ & .27 \\
\hline
\end{tabular}

Values given in picograms per milliliter [mean $(25 \%, 75 \%)$ ].

* Mann-Whitney rank sum test.

levels and birth weight (Spearman's $r=-0.14, p=0.48$ ) or gestational age (Spearman's $r=-0.19, p=0.32$ ). ET-1 weakly correlated with apoptosis (Spearman's $r=0.38, p=$ 0.04 ) but not with LDH levels (Spearman's $r=0.29, p=$ $0.13)$.

Cells in tracheal aspirate. Airway epithelial cells and neutrophils were the predominant cell types observed. No correlation was present between levels of bFGF, VEGF, and ET-1 versus cell density, proportion of the cells that were $\mathrm{WBC}$, proportion of the WBC that were neutrophils, and the absolute number of neutrophils/high power field (hpf) (data not shown; all $r<0.40$, all $p>0.05$ ). No correlation was present between the presence or absence of chorioamnionitis or poor outcome $\left(\right.$ death $\left./ \mathrm{BPD}_{28 \mathrm{~d}}\right)$ and the cell types or numbers observed in the tracheal aspirate (mean $\pm \mathrm{SD}$; death/$/ \mathrm{BPD}_{28 \mathrm{~d}}: 74 \pm 74$ cells/ hpf, $27 \pm 21 \%$ WBC, $63 \pm 30 \%$ neutrophils, $15 \pm 25$ neutrophils/hpf versus normal survivors: $71 \pm 46$ cells/hpf, 42 $\pm 23 \%$ WBC, $72 \pm 11 \%$ neutrophils, $17 \pm 13$ neutrophils/hpf).

\section{DISCUSSION}

This pilot study evaluated the association between PGF in tracheal aspirates of mechanically ventilated preterm infants and BPD, markers of lung injury, and antecedent chorioamnionitis. Elevated levels of bFGF in tracheal aspirates on the first day of life were associated with worse outcome $\left(\mathrm{BPD}_{28 \mathrm{~d}} /\right.$ death) and increased evidence of cell injury (LDH) and apoptosis (DNA fragmentation). VEGF and ET-1 did not demonstrate such an association, and all three PGF were not linked to chorioamnionitis.

Our study has some important limitations. Being a pilot study, the sample size was limited, increasing the likelihood of statistical error. Subsequent trials using a larger sample size are required to confirm these results. The sample size was limited as our center uses conservative indications for the initiation of mechanical ventilation in preterm neonates, and rapid weaning from the ventilator is the norm. Endotracheal suctioning is also not routinely performed on the first day of life unless there are excessive secretions or suspicion of tube occlusion. The study population is hence a higher-risk category of ventilated preterm infants. It is controversial whether tracheal aspirates should be corrected for dilution, using techniques such as urea dilution, protein levels, or secretory immunoglobulin A (SIgA) concentrations. We followed the recommendations of the European Respiratory Task Force on Bronchoalveolar Lavage in children (19) and did not correct our results for the dilution, although our procedure could be more accurately defined as tracheobronchial lavage rather than bronchoalveolar lavage. Increased vascular permeability and lung inflammation in sicker infants may lead to erroneous results after correction for urea dilution or protein concentration, as increased levels of urea or protein may not signify less dilution but a leakier air-epithelial interface. Another limitation of this and similar studies is that the origin of growth factors and other substances present in the tracheal aspirates cannot be determined with certainty.

There are some possible explanations for the association between higher bFGF and worse outcome. More research is required to evaluate the role and implications of bFGF in the preterm airway, as this is the first report to address the issue. Fibroproliferation is initiated early (within $24 \mathrm{~h}$ of diagnosis) in ARDS and impacts on outcome (20). bFGF is elevated in the epithelial lining fluid of adults with ARDS, but not in those without acute lung inflammation (18). It is possible that a similar process occurs in neonatal respiratory distress syndrome, and that bFGF is one of the stimuli inducing fibroproliferation. The association between bFGF and outcomes or markers of cell injury/apoptosis in preterm infants has not been described so far. Basic FGF is localized to airway epithelial cells and extracellular matrix in rat fetal lungs (1), and in both epithelial and mesenchymal cells in human fetuses (2). bFGF may modulate repair from lung injury $(21,22)$. The mechanism of bFGF release is unclear, as it lacks a signal sequence (although higher molecular weight forms contain a nuclear targeting sequence). It is likely that cell injury and inflammation lead to a release of bFGF with autocrine effects. This is in agreement with our observation that elevated levels of bFGF correlated with LDH and apoptosis markers, suggesting that cellular injury and apoptosis may lead to the bFGF release. We speculate that the cellular injury and apoptosis in combination with elevated bFGF may either indicate sufficient lung injury to cause mortality or $\mathrm{BPD}_{28 \mathrm{~d}}$, or may directly contribute at least in part to these outcomes. It is possible that tissue concentrations of bFGF are higher, compared with levels in the diluted tracheal aspirate, and may co-localize with sites of injury and repair processes.

VEGF is an endothelial cell mitogen that also regulates vascular permeability. VEGF is found mostly in bronchial epithelium and alveolar macrophages, and its receptor (Flt-1) is found in vascular endothelial cells and bronchial epithelial cells (14). Infants dying from BPD have dysmorphic alveolar capillaries in association with decreased VEGF mRNA and immunostaining, and decreased message for Flt-1 and the angiopoietin-1 receptor TIE-2 (17). Lassus et al. (23) observed a rapid postnatal increase in VEGF levels in tracheal aspirates from intubated preterm infants, without any correlation between VEGF and birth weight or gestational age. During d 4 and 7, infants developing $\mathrm{BPD}_{36 \mathrm{wk}}$ had lower VEGF than survivors without BPD (23). D'Angio et al. (24) noted a tripling of VEGF levels in BAL fluid between d 1 and 3, and higher lavage levels on $\mathrm{d} 1$ and 3 correlated with a lower gestational age, but not with the development of $\mathrm{BPD}_{36 \mathrm{wk}}$. Our study is in concurrence with that of Lassus et al. (14) and Bhatt et al. (17), as infants with worse outcome ( $\mathrm{BPD}_{28 \mathrm{~d}}$ or death) had a nonsignificant trend toward lower VEGF levels (median 
level of $114 \mathrm{pg} / \mathrm{mL}$ versus $290 \mathrm{pg} / \mathrm{mL}$ in survivors without $\mathrm{BPD}_{28 \mathrm{~d}}, p=0.13$ ). It must be emphasized that all studies to date, including ours, had small sample sizes and did not have sufficient statistical power to arrive at definite conclusions.

ET-1 is developmentally regulated (25) and is involved in the pathogenesis of related disorders such as ARDS (26). Niu et al. (15) observed in preterm infants that tracheal aspirate ET-1 was elevated in the first day in infants who later developed $\mathrm{BPD}_{36 \mathrm{wk}}$. However, in a study on 11 preterm neonates in the first week of life, Andersson et al. (27) concluded that higher ET-1 levels in tracheal aspirates were associated with lower mean airway pressures and oxygen concentration $\left(\mathrm{FiO}_{2}\right)$. Andersson et al. (27) did not find any correlation between ET-1 and gestational age and birth weight. Our study did not show any associations between ET-1 and outcome, or between ET-1 and birth weight and gestational age.

Other PGF that have not been evaluated in this study, such as EGF, transforming growth factor- $\alpha$, PDGF, and KGF (FGF7), are also known to be important in vivo in normal lung development in late fetal life and in repair from injury (8, 28-33).

Chorioamnionitis is a risk factor for poor outcome in preterm neonates $(34,35)$, and we have shown earlier that chorioamnionitis was associated with elevations of proinflammatory cytokines (IL-1 $\beta$, IL-6, IL-8, tumor necrosis factor- $\alpha$ ) (36). The high rate of $\mathrm{BPD}_{28 \mathrm{~d}} /$ death in this study may have been the result of the high incidence of chorioamnionitis (18 of 29 infants), which is known to predispose to BPD and mortality. However, the levels of bFGF, VEGF, and ET-1 were similar in infants with or without chorioamnionitis, suggesting that these growth factors may not have been involved in chorioamnionitis-induced lung pathology on the first day of life.

A larger study is required to confirm the association of bFGF with worse outcomes, especially with longer-term outcomes such as $\mathrm{BPD}_{36 \mathrm{wk}}$, pulmonary function in early childhood, and neurodevelopment. Basic research is necessary to determine whether the association is of a causal nature, and, if so, evaluate the possible therapies that may exploit this mechanism of disease.

\section{REFERENCES}

1. Han RN, Liu J, Tanswell AK, Post M 1992 Expression of basic fibroblast growth factor and receptor: immunolocalization studies in developing rat fetal lung. Pediatr Res 31:435-440

2. Gonzalez AM, Hill DJ, Logan A, Maher PA, Baird A 1996 Distribution of fibroblast growth factor (FGF)-2 and FGF receptor-1 messenger RNA expression and protein presence in the mid-trimester human fetus. Pediatr Res 39:375-385

3. Lebeche D, Malpel S, Cardoso WV 1999 Fibroblast growth factor interactions in the developing lung. Mech Dev 86:125-136

4. Tichelaar JW, Lu W, Whitsett JA 2000 Conditional expression of fibroblast growth factor-7 in the developing and mature lung. J Biol Chem 275:11858-11864

5. Chelly N, Mouhieddine-Gueddiche O-B, Barlier-Mur A-M, Chailley-Deu B, Bourbon JR 1999 Keratinocyte growth factor enhances maturation of fetal rat lung type II cells. Am J Respir Cell Mol Biol 20:423-432

6. Mendelson CR 2000 Role of transcription factors in fetal lung development and surfactant protein gene expression. Annu Rev Physiol 62:875-915

7. Warburton D, Zhao J, Berberich MA, Bernfield M 1999 Molecular embryology of the lung: then, now, and in the future Am J Physiol 276:L697-L704

8. Strandjord TP, Clark JG, Guralnick DE, Madtes DK 1995 Immunolocalization of transforming growth factor-alpha, epidermal growth factor (EGF) and EGF-receptor in normal and injured developing human lung. Pediatr Res 38:851-856

9. Chinoy MR, Zgleszewski SE, Cilley RE, Blewett CJ, Krummel TM, Reisher SR, Feinstein SI 1998 Influence of epidermal growth factor and transforming growth factor beta-1 on patterns of fetal mouse lung branching morphogenesis in organ culture. Pediatr Pulmonol 25:244-256

10. Chan TS, Lin CX, Chan WY, Chung SS, Chung SK 1995 Mouse preproendothelin-1 gene. cDNA cloning, sequence analysis and determination of sites of expression during embryonic development. Eur J Biochem 234:819-826

11. Giaid A, Polak JM, Gaitonde V, Hamid QA, Moscoso G, Legon S, Uwanogho D, Roncalli M, Shinmi O, Sawamura T 1991 Distribution of endothelin-like immunoreactivity and mRNA in the developing and adult human lung. Am J Respir Cell Mol Biol 4:50-58

12. Souza P, Tanswell AK, Post M 1996 Different roles for PDGF-alpha and -beta receptors in embryonic lung development. Am J Respir Cell Mol Biol 15:551-562

13. Lindahl P, Karlsson L, Hellstrom M, Gebre-Medhin S, Willetts K, Heath JK, Betsholtz C 1997 Alveogenesis failure in PDGF-A-deficient mice is coupled to lack of distal spreading of alveolar smooth muscle cell progenitors during lung development. Development 124:3943-3953

14. Lassus P, Turanlahti M, Heikkila P, Andersson LC, Nupponen I, Sarnesto A, Andersson S 2001 Pulmonary vascular endothelial growth factor and Flt-1 in fetuses, in acute and chronic lung disease, and in persistent pulmonary hypertension of the newborn. Am J Respir Crit Care Med 164:1981-1987

15. Niu JO, Munshi UK, Siddiq MM, Parton LA 1998 Early increase in endothelin-1 in tracheal aspirates of preterm infants: correlation with bronchopulmonary dysplasia. J Pediatr 132:965-970

16. Kojima T, Hattori K, Hirata Y, Aoki T, Sasai-Takedatsu M, Kino M, Kobayashi Y 1996 Endothelin-1 has a priming effect on production of superoxide anion by alveolar macrophages: its possible correlation with bronchopulmonary dysplasia. Pediatr Res 39:112-116

17. Bhatt AJ, Pryhuber GS, Huyck H, Watkins RH, Metlay LA, Maniscalco WM 2001 Disrupted pulmonary vasculature and decreased vascular endothelial growth factor, Flt-1, and TIE-2 in human infants dying with bronchopulmonary dysplasia. Am J Respir Crit Care Med 164:1971-1980

18. Ishizaka A, Watanabe M, Yamashita T, Ogawa Y, Koh H, Hasegawa N, Nakamura H, Asano K, Yamaguchi K, Kotani M, Kotani T, Morisaki H, Takeda J, Kobayashi K, Ogawa S 2001 New bronchoscopic microsample probe to measure the biochemical constituents in epithelial lining fluid of patients with acute respiratory distress syndrome. Crit Care Med 29:896-898

19. ERS Task Force on Bronchoalveolar Lavage in Children 2000 Bronchoalveolar lavage in children. Eur Respir J 15:217-231

20. Marshall RP, Bellingan G, Webb S, Puddicombe A, Goldsack N, McAnulty RJ, Laurent GJ 2000 Fibroproliferation occurs early in the acute respiratory distress syndrome and impacts on outcome. Am J Respir Crit Care Med 162: 1783-1788

21. Powers MR, Planck SR, Berger J, Wall MA, Rosenbaum JT 1994 Increased expression of basic fibroblast growth factor in hyperoxic-injured mouse lung. J Cell Biochem 56:536-543

22. Bretell LM, McGowan SE 1994 Basic fibroblast growth factor decreases elastin production by neonatal rat lung fibroblasts. Am J Respir Cell Mol Biol 10:306-315

23. Lassus P, Ristimaki A, Ylikorkala O, Viinikka L, Andersson S 1999 Vascular endothelial growth factor in human preterm lung. Am J Respir Crit Care Med 159:1429-1433

24. D’Angio CT, Maniscalco WM, Ryan RM, Avissar NE, Basavegowda K, Sinkin RA 1999 Vascular endothelial growth factor in pulmonary lavage fluid from premature infants: effects of age and postnatal dexamethasone. Biol Neonate 76:266-273

25. Ivy DD, Le Cras TD, Parker TA, Zenge JP, Jakkula M, Markham NE, Kinsella JP, Abman SH 2000 Developmental changes in endothelin expression and activity in the ovine fetal lung. Am J Physiol 278:L785-L793

26. Albertine KH, Wang ZM, Michael JR 1999 Expression of endothelial nitric oxide synthase, inducible nitric oxide synthase, and endothelin-1 in lungs of subjects who died with ARDS. Chest 116:101S-102S

27. Andersson S, Merritt TA, Orpana A, Viinikka L, Ylikorkala O 1997 High endothelin-1 in the airways of preterm infants is associated with less severe respiratory distress during the early postnatal period. Pediatrics 99:545-547

28. Allam M, Martinet N, Gallati H, Vaillant P, Hosang M, Martinet Y 1993 Plateletderived growth factor $\mathrm{AA}$ and $\mathrm{AB}$ dimers are present in normal human epithelial lining fluid. Eur Respir J 6:1162-1168

29. Snyder LS, Hertz MI, Peterson MS, Harmon KR, Marinelli WA, Henke CA, Greenheck JR, Chen B, Bitterman PB 1991 Acute lung injury. Pathogenesis of intraalveolar fibrosis. J Clin Invest 88:663-673

30. Hoyle GW, Li J, Finkelstein JB, Eisenberg T, Liu JY, Lasky JA, Athas G, Morris GF, Brody AR 1999 Emphysematous lesions, inflammation, and fibrosis in the lungs of transgenic mice overexpressing platelet-derived growth factor. Am J Pathol 154:1763-1775

31. Prince LS, Karp PH, Moninger TO, Welsh MJ 2001 KGF alters gene expression in human airway epithelia: potential regulation of the inflammatory response. Physiol Genomics 6:81-89

32. Waters CM, Savla U 1999 Keratinocyte growth factor accelerates wound closure in airway epithelium during cyclic mechanical strain. J Cell Physiol 181:424-432

33. Welsh DA, Summer WR, Dobard EP, Nelson S, Mason CM 2000 Keratinocyte growth factor prevents ventilator-induced lung injury in an ex vivo rat model. Am J Respir Crit Care Med 162:1081-1086

34. Hallman M 1999 Cytokines, pulmonary surfactant and consequences of intrauterine infection. Biol Neonate 76(suppl 1):2-9

35. Elimian A, Verma U, Beneck D, Cipriano R, Visintainer P, Tejani N 2000 Histologic chorioamnionitis, antenatal steroids, and perinatal outcomes. Obstet Gynecol 96:333336

36. Novak ZE, Carlo WA, Faye-Petersen OM, Vu LH, Mestecky J 2001 The effect of chorioamnionitis on cellular expression of inflammatory cytokines in neonatal lung cells. Pediatr Res 49:408A(abstr) 